\title{
A good chimney requires a good sweep
}

\author{
Viktor Hraska, MD, PhD, and Ronald K. Woods, MD, PhD
}

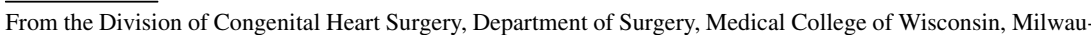
kee, Wis.

Disclosures: Authors have nothing to disclose with regard to commercial support.

Received for publication May 16, 2017; accepted for publication May 18, 2017; available ahead of print June 13 , 2017.

Address for reprints: Viktor Hraska, MD, PhD, Division of Congenital Heart Surgery, Department of Surgery, Medical College of Wisconsin, 9000 W Wisconsin Ave, B730, Milwaukee, WI 53226 (E-mail: vhraska@ chw.org).

J Thorac Cardiovasc Surg 2017; 154:e55

$0022-5223 / \$ 36.00$

Copyright (c) 2017 by The American Association for Thoracic Surgery

http://dx.doi.org/10.1016/j.jtcvs.2017.05.064
}

In this issue of the Journal, Asada and colleagues ${ }^{1}$ describe an innovative variation of autologous reconstruction of the aortic arch in the Norwood procedure. They describe this procedure for a patient with hypoplastic left heart syndrome who had undergone neonatal branch pulmonary artery (PA) banding (as well as other repairs), followed by the Norwood procedure at approximately 2 months of age. The key element of their "chimney reconstruction" is division of the main PA very distally for the anterior $240^{\circ}$, extending the division line proximally into the posterior pulmonary sinus to create a U-shaped patch. This sets up the following important technical maneuvers: (1) with primary closure of the posterior defect in the main PA, the main PA is reduced in diameter while maintaining adequate length; and (2) the harvested U-shaped flap is used to create a patent pulmonary bifurcation without the need for prosthetic material. The gradual tapering of the neo-ascending aorta is purported to offer the dual advantages of (1) more space under the arch to prevent compression of the left PA or bronchus and (2) a smoother caliber transition of the ascending aorta into the aortic arch, which might provide less energy loss.

This case report raises several technical issues. Although the posterior U-shaped flap permits a more distal PA incision anteriorly, the distal limit of this incision is inherent to each patient's anatomy. It is very likely that the patient of Asada and colleagues ${ }^{1}$ had a very large and long PA trunk, as is typical after an extended period of branch PA banding. It is therefore unclear whether this technique would be uniformly effective for all primary Norwood procedures. The second issue is that the reconstructed ascending aorta, aortic arch, and descending aorta lie in different planes. Anteroposterior movement of these planes is more pronounced in the context of a long distal transverse arch. Under these circumstances the risk of compression of the branch PA or bronchus might be higher because the PA trunk is either "pulled" more posteriorly to reach the descending aorta, or because the reconstructed descending aorta is "pulled" more superiorly and anteriorly. A third issue is that this technique will be more likely to result in

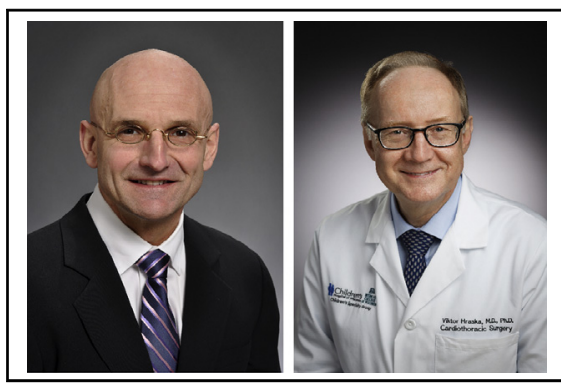

Ronald K. Woods, MD, PhD (left), and Viktor Hraska, $\mathrm{MD}, \mathrm{PhD}$ (right)

\section{Central Message}

Tapering of the proximal neo-ascending aorta might provide a reconstructed aortic arch with lower energy loss.

See Article page e51.

a more gothic-shaped arch, an anatomic characteristic that has been associated with greater energy loss and risk for recurrent stenosis. ${ }^{2}$ An excellent result in a single patient and a reassuring computational fluid dynamics study are inadequate to negate this concern. A final issue is that it would be difficult to use this technique in certain variants of single-ventricle anatomy with either transposed great vessels or an interrupted aortic arch.

Given the limited availability of native tissues in patients with hypoplastic left heart syndrome and the excellent results of arch reconstruction obtained by interdigitated repair with patch augmentation,,$^{3,4}$ it is not surprising that many surgeons continue to rely on patch augmentation for arch reconstruction instead of autologous arch reconstruction.

We commend Asada and colleagues ${ }^{1}$ for introducing yet another technique of arch reconstruction. We await further data to verify its effectiveness.

\section{References}

1. Asada S, Yamagishi M, Itatani K, Yaku H. Chimney reconstruction of the aortic arch in the Norwood procedure. J Thorac Cardiovasc Surg. 2017;154:e51-4.

2. Voges I, Jerosch-Herold M, Hedderich J, Westphal C, Hart C, Helle M, et al. Maladaptive aortic properties in children after palliation of hypoplastic left heart syndrome assessed by cardiovascular magnetic resonance imaging. Circulation. 2010; $122: 1068-76$.

3. Burkhart H, Ashburn D, Konstantinov I, De Oliveira NC, Benson L, Williams WG et al. Interdigitating arch reconstruction eliminates recurrent coarctation after the Norwood procedure. J Thorac Cardiovasc Surg. 2005;130:61-5.

4. Lamers L, Frommelt P, Mussatto K, Jaquiss R, Mitchell M, Tweddell J. Coarctectomy combined with an interdigitating arch reconstruction results in a lower incidence of recurrent arch obstruction after the Norwood procedure than coarctectomy alone. J Thorac Cardiovasc Surg. 2012;143: 1098-102. 